\title{
A MINIREVIEW OF CELLULOSE NANOCRYSTALS AND ITS POTENTIAL INTEGRATION AS CO-PRODUCT IN BIOETHANOL PRODUCTION
}

\author{
NELSON DURÁN $N^{1,2, *}$, ANA P. LEMES ${ }^{1,3}$, MARCELA DURÁN ${ }^{1}, J U A N I T A ~ F R E E R{ }^{4}$, JAIME BAEZA4 \\ ${ }^{1}$ Institute of Chemistry, Biological Chemistry Laboratory, Universidade Estadual de Campinas, C.P. 6154, CEP 13083-970, Campinas S.P., Brazil. \\ ${ }^{2}$ Center of Natural and Human Sciences, Universidade Federal do ABC, CEP 09.210-170, Santo André, SP., Brazil. \\ ${ }^{3}$ Universidade Federal de São Paulo, UNIFESP, São Jose dos Campos, SP, Brazil \\ ${ }^{4}$ Renewable Resources Laboratory, Biotechnology Center, Universidad de Concepción, Concepción, Chile.
}

(Received: September 9, 2010 - Accepted: May 15, 2011)

\begin{abstract}
Cellulose nanocrystals appeared as important bio-based products and the collected information in term of production, characterization and application suggest that this nanomaterial could be easily extrapolated to bioethanol production. This review describes recent published syntheses using chemical and enzymatic hydrolyses and different preparations such as high pressure homogenization. Their industrial and medical applications, such as controled of delivery carriers, suggest a large projection of this nanomaterial. The most important aspect in this collected data is the potential to decrease significantly the final cost of the enzymes or the hydrolysis pre-treatment of lignocellulosic materials of all bioethanol processes in such a way that it could be economically feasible from materials such as bagasse, straw or wood resources.
\end{abstract}

Keywords Cellulose nanocrystals · Bioethanol · Biorefineries · Lignocellulosics

\section{INTRODUCTION}

As a first step, it is important to define the cellulose structures that will be mentioned in this review. ${ }^{1}$ The term fibril is used by various researchers to describe relatively long and thin pieces of cellulosic materials; the term nanofiber is used to emphasize cases where small cellulosic fibrous materials have a different behavior compared to larger cellulosic fibers (fiber/strand: $>>1$ aspect ratio). They have unique physico-chemical properties different from microfibers or larger structures. Long and straight crystals of cellulose are usually called whiskers. Nanofibers isolated from tunicate that resemble a cat's whiskers have been reported $(8-20 \mathrm{~nm}$ in thikness and lengths $1 \mu \mathrm{m})$. However, there are many synonyms for these cellulose nanocrystals, such as nanorod, rod-like cellulose microcrystals and nanowires. Cellulose nanospheres (40$60 \mathrm{~nm})^{2}$, spherical cellulose nanocrystals $(60 \mathrm{~nm})^{3}$ and cellulose nanoballs $(80 \mathrm{~nm})^{4}$ have also been published. In some cases crystalline nanocellulosic elements appear wider than the sizes mentioned above, and probably are related to lateral bonding between adjacent crystallites during biosynthesis. ${ }^{5}$

\section{General aspects of nanotechnology in forest products}

It is general agreed that nanotechnology has the potential to change completely the forest product industry through improvements of the actual products and designing new applications of cellulose with different properties. ${ }^{6}$

It is known that cellulose is the most abundant, natural, renewable and biodegradable polymer that occurs as a nanostructure in plants, giving resistance. The most important aspects of this material are its bioavailability. ${ }^{7}$

The forest-products industry, a $\$ 260$ billion sector in the US economy with a pulp production of around 53 millions of metric tons, is interested in nanotechnology, considering that the production of cellulose nanocrystals is important throughout the world. ${ }^{8}$ The U.S is studying this important issue in a collaborative consortium (a public-private partnership) investigating material reinforced with natural polymeric nanoparticles. ${ }^{7}$ Brazil and Chile follows Canada, Sweden and Finland, with pulp production of around 7 and 2 million of metric tons, respectively. ${ }^{8}$

Engineering fiber and design of lignocellulosics or rod-like cellulose nanoparticles and micro fibrils to get high value-added products with special performance can reach new markets through nanotechnology., ${ }^{9,10}$

In view of these facts, there is a need to develop manufacturing metrology infrastructure for determination of properties for these nanoscale materials and the final products. ${ }^{11,12}$

According with Lima and Borsali ${ }^{13}$, charged rod-shaped cellulose whiskers are a good model for understanding the rod-particles behavior with polyelectrolytic properties. Mechanical behavior was pointed out as an important feature of the cellulose whiskers as fillers for reinforcements in different polymer matrices; this reinforcing effect is mainly because of the percolation effect.

There is great potential of making nanocomposites with biodegradable characteristics based on nanoparticles arising from wood. However, understanding the polymer-nanoparticle interface is necessary for obtaining nanocomposites with good mechanical performance, as discussed in the review of Gacitua et al. ${ }^{14}$

These aspects were reinforced in the publication by Samir et al..$^{15}$ in which an exhaustive revision of the literature between 1995-2005 showed that the use of high aspect ratio cellulose nanocrystals induced a mechanical percolation phenomenon leading to emphasizing the unusual mechanical properties of these materials. One of the challenges in nanocomposites are an efficient nanocrystal separation from the natural resources, besides the compatibilization of the nanoreinforcement with the matrix, development of new methods for material processing, and the no less important the energy factor. ${ }^{16}$

An excellent review on cellulose whiskers summarized the dimensional characteristics with their respective sources, description of isolation processes, hydrolysis conditions, and techniques of determination and performance of this material in suspension and in polymeric matrixes. Comments on dispersity, related to their tendency towards agglomeration, and their compatibility with commercial hydrophobic polymers were also discussed. ${ }^{17}$

A recent review showed that nanocrystalline cellulose exhibited intriguing scientific and engineering discoveries and advancements. However, the authors pointed out that, the field is still in its infancy and open to opportunities for new advancements and discoveries..$^{18}$ Other authors showed that cellulose nanocrystals are attractive material to incorporate into composites because they can introduce additional strength gains with highly versatile chemical functionality. ${ }^{19}$

Methods used to isolate cellulose nanofibres (nanowhiskers, nanofibrils), processing and characterization of cellulose nanocomposites, new developments in the area and applications were recently discussed. Cellulose nanofibres extracted from plants by acid hydrolysis (nanowhiskers), mechanical treatment and those that occur naturally (tunicate nanowhiskers) or under culturing conditions (bacterial cellulose nanofibrils) ${ }^{20-22}$, its application on bio-nanocomposites ${ }^{23}$ and processing-structure-property perspective on recent advances in cellulose nanoparticles and composites produced from 
them ${ }^{24}$ have also been discussed .

\section{Synthesis of cellulose nanocrystals by chemical hydrolysis}

Classical hydrolyses obtaining cellulose rod-like nanocrystals ${ }^{25}$ or nanocrystal systems from hardwood and softwood ${ }^{26}$ or whiskers ${ }^{27}$ or rod-like nanoparticles ${ }^{28}$ have been described.

Cellulose nanocrystals from pure ramie fibers and fresh specimens of tunicin (Microscosmus fulcatus) were extracted from the external wall of $M$. fulcatus. Ramie fibers were submitted to acid hydrolysis and the nanocrystal suspensions, with the appropriate concentrations, were sonicated. The surface grafted sulfate groups, negatively charged, provide that the rod-like cellulose nanocrystals form stable layers at the air-water interface in the presence of a cationic amphiphilic molecule such as dioctadecyldimethylammonium. ${ }^{29}$

The dispersion of tunicate (Styela clava) cellulose whiskers obtained from hydrolysis with sulfuric acid or with hydrochloric acid was evaluated in water, N,N-dimethyl formamide (DMF), dimethyl sulfoxide (DMSO), and $\mathrm{N}$-methyl pyrrolidone (NMP). The presence of sulfate ester moieties on the whisker surfaces after hydrolysis with sulfuric acid was the determining factor in their dispersability in polar aprotic solvents. Tunicate whisker dispersions in organic solvents could be interesting intermediates for the preparation of polymer/tunicate whisker nanocomposites. ${ }^{30}$

A novel spherical cellulose nanocrystal suspension was prepared by hydrolysis of microcrystalline cellulose with mixed acids under ultrasonic treatment. Different colors and liquid crystalline structure were observed at different concentration. These characteristics might give rise to potential applications as functional materials. ${ }^{3,31}$

Sesame husk chemically treated mass was subjected to acid hydrolysis with $35 \%$ sulfuric acid and cellulose microwhiskers were released from the husk, forming a white colloidal suspension and leaving a solid residue at the bottom and these microwhiskers were subjected to homogenization, after which spherical cellulose nanoparticles (CNPs) were produced having diameters in the range of $30-120 \mathrm{~nm}^{32}$

Cellulose nanowhiskers from cotton linter were hydrolyzed by hydrochloric acid and the average length and diameter were 244 and $22 \mathrm{~nm}$, respectively. Similar values for length and diameter $(272$ and $13 \mathrm{~nm})$ were obtained with sulfuric acid. This study also established a new methodology for size characterization of polydisperse spheroidal nanoparticles. ${ }^{33}$

The cotton linters were hydrolyzed with sulfuric acid and the suspensions were washed by centrifugation, dialyzed against distilled water and ultrasonicated. A property of nanocrystals obtained from sulfuric acid hydrolysis of native cellulose is their facility of self-assembling into ordered chiral nematic phases above a critical concentration that depends on axial ratio and ionic strength. Multilayered films of alternating sheets of rigid cellulose nanocrystals and flexible poly(allylamine hydrochloride) prepared by the layer-by-layer assembly technique were discussed. ${ }^{34}$

Hydrolysis of cellulose (Cotton-Avicel or tunicate) with sulfuric acid showed that cellulose particles were flat objects constituted by elementary crystallites whose lateral adhesion was resistant against hydrolysis and sonication treatments. In the case of tunicin whiskers twisted ribbons with an estimated pitch around 2.4-3.2 $\mu \mathrm{m}$ were observed. ${ }^{5}$

The production of cellulose nanocrystals in deionized water from microcrystalline wood cellulose and recycled wood pulp using sono-chemicalassisted hydrolysis showed that sizes were similar (21-23 nm). In the presence of maleic acid sono-chemical assisted hydrolysis of microcrystalline cellulose produced cellulose nanocrystals which were cylindrical in shape and had dimensions of $65 \pm 19 \mathrm{~nm}$ (length) and $15 \mathrm{~nm}$ (width). ${ }^{35,36}$

A controlled alkali and acid hydrolysis after Soxhlet extraction of bleached fiber from grass fibers (Zoysa japonica and tenuifolia) in ethanol and water gave a mixture of micro/nano fiber that were converted into cellulose nanowhiskers $(10-65 \mathrm{~nm})$ by sonication. The sizes were associated with the period of treatment applied to the process. The direct acid treatment also produces some nanofibers on the surface of cellulose bundles in the grass but this depends on bleaching and temperature conditions. ${ }^{37}$

Comparing dried and never-dried chemical pulps that were subjected to strong sulfuric acid hydrolysis indicated that the process was facilitated by drying the fibers beforehand, especially by thermal drying over $100^{\circ} \mathrm{C}$. Probably, the irreversible aggregation of cellulose microfibrils during drying caused tensions in the amorphous regions of the microfibrils and then these regions were highly susceptible to acid hydrolysis. ${ }^{38}$

It was isolated cellulose nanostructures from never-dried cellulose wood pulp, in sheet-form $(\sim 1 \mathrm{~nm}$ thinckness and $\sim 100 \mathrm{~nm}$ length) through 2,2,6,6-tetramethylpiperidine-1-oxy radial (TEMPO)-mediated oxidation providing an acid content of $1.12 \mathrm{mmol} / \mathrm{g}$ combined with extensive ultrasonication. The authors suggested that these results are evidences that the intersheet van der Waals bonding of the cellulose fibril is weaker than the intrasheet hydrogen bonding of the cellulose microfibril. These nanoparfibrils were easily produced with a high specific surface area and funtionalyzed groups for different applications. ${ }^{39}$

Coconut fiber was used to prepare cellulose nanocrystals by sulfuric acid hydrolysis under different conditions of reaction time. Comparison of the hydrolysis degree as a function of fiber extraction time demonstrated that the length of cellulose nanocrystals was greater for shorter extraction times. The results promoted the use of coconut fibers as a novel renewable source of nanocrystals with potential as reinforcing agents in nanocomposites. ${ }^{40,41}$

Colloidal suspensions of cellulose whiskers in water were prepared by sulfuric acid hydrolysis of branch-barks of mulberry (Morus alba L.), centrifuged and after sonication exhibited a size range from 20 to $40 \mathrm{~nm}$ with lengths of $400-500 \mathrm{~nm}^{42}$

Synthesis of cellulose nanocrystals by high pressure homogenization

Another interesting cellulose material is microfibrillated cellulose, composed of liberated semicrystalline microfibrils, normally produced using high-pressure homogenization of wood fibers in water. Microfibrillated cellulose (MFC) was first introduced by Turbak et al. ${ }^{43}$, who reported that the width of the MFC fibrils was between 25 and $100 \mathrm{~nm}$, while the length was longer.

Cellulose pellets from hard wood cellulose fibers were dispersed in water with a concentration of $0.2 \mathrm{wt} \%$, forming a slurry by stirring. The fibrillation of cellulose fibers was made using high pressure homogenization obtaining nanofibrils with around 50-100 nm diameters. ${ }^{44}$

MFC were prepared from sulfite softwood-dissolving pulp and after this pretreatment, the fibers were homogenized using a high-pressure fluidizer at $2 \mathrm{wt} \%$. The size of the fibrils showed that they have a cross-section between 5 and $15 \mathrm{~nm}$ and that the length can be more than $1 \mu \mathrm{m} .{ }^{45}$ Similarly MFC were prepared from microcrystalline cellulose (MCC) starting materials by application of a high-pressure homogenizer to a commercial microcrystal cellulose previously dispersed by a Turrax. The cellulose fibrils were in the range from 28 to $100 \mathrm{~nm}^{46}$

MFC was extracted from the rachis of the date palm and, after bleaching, it was disintegrated by high pressure homogenization. The solid content of the suspensions was around $0.3 \mathrm{wt} \%$. The lowest lateral size of the microfibrild were of the order of some nanometers $(5-10 \mathrm{~nm})$ and also showed some thicker fibrils bundles (around $100 \mathrm{~nm}$ ) and some short fibrils $\left(<2 \mu \mathrm{m}\right.$ in length). ${ }^{47}$

\section{Synthesis of cellulose nanocrystals by enzymatic hydrolysis}

A new concept to prepare nanoscale cellulose fibrils has been published, where enzymatic hydrolysis was used in combination with mechanical shearing and high-pressure homogenization to produce defibrilation of the fiber wall to obtain fibrils with a diameter of around 5-6 nm and aggregates around 10-20 $\mathrm{nm}^{48}$

A preparation method using cellulase to obtain cellulose nanocrystals made from cotton fibers, with prior treatment by an ultrasonic cell pulverizer, was optimized and the production had good monodispersity. ${ }^{49}$

The treatment of recycled pulp with endoglucanase enzyme using different conditions produced cellulose nanocrystals with different yields. The yields of cellulose nanocrystals were higher with water and endoglucanase at both modes of heating investigated. Microwave heating at each treatment gave a higher yield than conventional heating $(30-80 \mathrm{~nm}$ and a length of $100 \mathrm{~nm}$ to $1.80 \mathrm{um})$. In all treatments, the presence of cellulose nanocrystals was confirmed by flow birefringence..$^{50}$

The substrate used for production of bacterial cellulose by Acetobacter xylinum in a static fermentation can influence in the crystallinity degree of cellulose where the crystallinity of glucose and bark/glucose medium were $56 \%$ (cellulose type I) and $28 \%$, respectively, demonstrating that the bacterial cellulose network formed with rice bark as substrate is less crystalline. The $\mathrm{X}$-ray diffraction pattern from rice bark/glucose medium under aeration showed that the crystal type changes from cellulose I to cellulose II, as shown by the peaks shifting to lower Bragg angles. The authors found that the nanostructurated biopolymer obtained from the rice bark/glucose medium had micro- and nanospheres linked to nanofibers of cellulose. ${ }^{2}$

Cellulase hydrolysis of bacterial cellulose (produced by Acetobacter xylinum ) produced nanocrystals (100-300 nm length, 10-15 nm diameter) and these materials exhibited better mechanical and thermal properties as compared to the nanocrystals obtained from sulfuric acid hydrolysis. ${ }^{51}$

Trichoderma reesei (cellulolytic fungus) under controlled hydrolysis 
conditions produced cellulose nanowhiskers from microcrystalline cellulose The zeta potential of fungal hydrolyzed was higher than de cellulose nanowhiskers from that prepared by acid hydrolysis. Then, the fungal hydrolysis resulted in cellulose nanowhiskers without any surface modification. ${ }^{52}$

\section{Recent Applications of cellulose nanocrystals}

In a three-step reaction pathway, fluorescent FITC molecules were covalently attached to the surface of cellulose nanocrystals that were prepared from milled dissolving grade softwood sulfite pulp using sulfuric acid Fluorescently labeled cellulose nanocrystals enable use in the interaction of cellulose nanocrystals with cells and the biodistribution of cellulose nanocrystals in vivo. ${ }^{53}$

A composite of rod-like cellulose nanocrystals extracted from ramie fibers and starch nanocrystals extracted from waxy maize starch with poly $(\varepsilon-$ caprolactone (PCL) were organized as a semicrystalline shell on the surface of the nanoparticles. This nanocomposite displayed both a high modulus and a good ductility (elongation at break) different from unmodified PCL. ${ }^{54}$

Cellulose nanowhiskers were prepared by sulfuric acid hydrolysis of microcrystalline cellulose, dialyzed and coated with polyethylene glycol (PEG) solution. This PEG solution was freeze-dried and ground into fine powder. The composites of poly(3-hydroxybutyrate-co-3-hydroxyvalerate) (PHBV)/cellulose nanowhiskers was fabricated by solution casting using N,Ndimethylformamide as the solvent. The composite exhibited improved tensile strength and modulus and increased glass transition temperature. Polyethylene glycol (PEG) as a compatibilizer did not avoid cellulose nanowhisker agglomeration. ${ }^{55}$

Cellulose nanoparticles isolated by the sulfuric acid hydrolysis from commercial microcrystalline cellulose were rod-like whiskers with an average size of about $340 \mathrm{~nm}$. The tensile modulus and strength of cellulose nanoparticles-reinforced poly(vinyl alcohol) nanocomposite was improved with an increase in the nanoparticles content (at $5 \mathrm{wt} \%)^{56}$

Poly(3-hydroxybutyrate-co-3-hydroxyvalerate(PHBV)/cellulose nanocrystals were prepared and compared with $\mathrm{PHBV} /$ microcrystalline cellulose composites. The cellulose nanocrystals were prepared by the sulfuric acid methodology. The Young's modulus and tensile strength were significantly improved ${ }^{57}$ PHBV/cellulose nanocomposites produced by solution casting technique and compatibilized with PEG improved in Young's modulus and in tensile strength. Mechanical and dynamic mechanical results indicated that cellulose nanoparticles was an effective reinforcing agent for PHBV. ${ }^{58}$

Cellulose nanowhiskers from cotton were prepared using sulfuric acid and dispersions of these solutions were used for the fabrication of gels. This aerogel was dispersed in DMF via sonication and this solution was employed for the production of solution cast nanocomposites. Nanowhiskers and ethylene oxide/ epichlorohydrin copolymer (EO-EPI copolymer) were produced and displayed the maximum mechanical reinforcement predicted by the percolation model. ${ }^{59}$

Cellulose nanocrystals were extracted from rachis of the date palm tree (Phoenix L dactylifera) and used as nano-reinforcement in natural rubber latex. Morphological, thermal and mechanical properties of these nanocomposites were determined and the interest of the authors was the influence of the filler content on the mechanical properties of these materials, in both the linear and nonlinear ranges. The average length and diameter of cellulose whiskers extracted from the rachis of the date palm tree were around $260 \mathrm{~nm}$ and 6.1 $\mathrm{nm}$, respectively. ${ }^{60}$

Cassava starch reinforced with waxy starch nanocrystals increased enormously the rubbery storage modulus and showed a significant decrease in water vapor permeability. The composite was more amorphous than the neat matrix, which is probably due to the higher equilibrium water content in the composites. TGA confirmed this result and the derivative curve suggested the formation of hydrogen bonding between glycerol and the nanocrystals. The decrease of the permeability suggests that the nanocrystals were well dispersed, with few filler/filler interactions. ${ }^{61}$

Ramie fibers were treated with $\mathrm{NaOH}$ solution and then submitted to an acid hydrolysis treatment with sulfuric acid and homogenized with a Turrax homogenizer, followed by filtering to obtain nanowhiskers. The surface of the ramie cellulose whiskers were chemically modified, presenting different lengths of the aliphatic chain by an esterification reaction. The functionalized nanowhiskers and nonfunctionalized ones were extruded with low density polyethylene (LDPE) to prepare nanocomposite materials. Elongation at break was enhanced when certain amounts of long chains were grafted on the surface of the nanoparticles. ${ }^{62}$

Isolation of cellulose nanofibres and nanowhiskers from different sources, and processing technologies for the composites, are fundamental in the development of composites. One of the main difficulties is to disperse the reinforcement in the polymer matrix without degradation of the biopolymer or the reinforcing phase. It is possible to resolve this through enhancement of the compatibility between nanofibres and the matrix and by using suitable processing methods. Use of a magnetic field for the alignment of the nanocelluloses was discussed and the nanocomposites' mechanical properties, based on the findings from different studies and some examples of future nanocomposites, have been discussed. ${ }^{63}$

Pure cotton was dispersed in sulfuric solution and, after stirring, centrifugation, dialysis, freeze-drying and sonication, the material was esterified and then an atom transfer radical polymerization with styrene was carried out to get cellulose-nanocrystal-g-polystyrene. By this method cellulose nanoparticles were produced with varying grafting densities (by altering the extent of initiator surface modification) and varying polymer brush length (through polymerization control). The nanocrystal-g-polystyrene particles were tested for their capacity to absorb 1,2,4-trichlorobenzene from water. This material efficiently absorbed the pollutant with faster absorption kinetics, compared to simple adsorption for nonmodified nanocrystals. ${ }^{64}$

Syngonanthus nitens (Capim Dourado) fibers were extracted and hydrolyzed in sulfuric acid. Natural rubber nanocomposite films reinforced with these cellulose whiskers by film casting showed that the reinforcing effect was observed above the glass transition temperature of the matrix. Modulus and strength properties were higher than those observed for other polysaccharide nanocrystals and cellulose whiskers extracted from other sources. ${ }^{65}$

Previously, a PLA nanocomposite and cellulose whiskers based on wood that were prepared by acid hydrolysis of microcrystalline cellulose were characterized by field emission scanning electron microscopy (FESEM) and by TEM ${ }^{6}{ }^{6}$ Recently, crystalline cellulose extracted from grass by alkali, acid, and mechanical treatments, to be used as filler to enhance the mechanical properties of PLA showed that the properties largely depended on the concentration of filler. The thermal resistance was decreased in comparison to the neat matrix. ${ }^{67}$

Composite films of PLA with cellulose nanofibres from acid hydrolysis of flax yarns ( $20 \mathrm{~nm}$ in diameter and $300 \mathrm{~nm}$ long) were prepared by solution casting. The composite films and a solution cast pure PLA film showed a good transparency. The tensile strength of the composite increased compared to pure PLA film. Comparing the amorphous with the crystalline composites, flax cellulose appeared to facilitate nucleation and subsequent crystallization of PLA more effectively than the amorphous one. ${ }^{68}$

Materials were obtained by introducing percolating networks of cellulose whiskers isolated from cotton into poly(vinyl acetate). After exposure of these materials to simulate physiological conditions (immersion in artificial cerebrospinal fluid), all nanocomposites showed a decrease in the tensile storage moduli (E'), with low swelling. The decreased swelling was an advantage for the use of these materials as substrates for intracortical electrodes and other biomedical applications. ${ }^{69}$

Glucomannans were mixed with cellulose nanowhiskers to form composite films and fiberlike or rodlike structures were observed, depending on the glucomannan added. The tensile strength of unplasticized glucomannan films increased with increasing cellulose nanowhisker content, but the mechanical properties of the plasticized films were not affected by the addition of the nanowhiskers. This it was most probably due to accumulation of glycerol as plasticizer in the cellulose nanowhiskers-matrix interface..$^{70}$

The layer-by-layer assembly technique was used to prepare a new biodegradable and biocompatible nanocomposite from cellulose nanowhiskers, previously obtained from sulfuric acid hydrolysis of eucalyptus wood pulp and sonication. Two renewable biobased materials, chitosan polymer and cellulose nanowhiskers, were used. A high density and a homogeneous distribution of cellulose nanowhiskers adsorbed on each chitosan layer were found. ${ }^{71}$

Polyurethanes with the addition of a small percentages of cellulose nanocrystals, introduced during the copolymerization reaction or incorporated after the polymerization, induced changes in the microstructure of the polymers, affecting the thermal and mechanical performance of the composite. The sequence of addition of the nanoparticles was important for the resulting properties. Depending of this addition the nanocomposite can increase the modulus of the nanocomposite and can show higher deformability and retain or shape memory, or reduce deformability and eraser or shape memory of the polymers. ${ }^{72-74}$

The mechanically induced molecular deformation of cellulose nanowhiskers from tunicates and cotton embedded in subpercolation concentration in an epoxy resin matrix showed that tunicate nanowiskers exhibited a greater level of stress transfer than the one obtained from cotton. It was suggested that this was due to the higher aspect ratio of the tunicate nanowisker nanocomposite and the absence of charge on the tunicate related to the cotton nanowiskers. ${ }^{75}$ 
When a polymethylmethacrylate nanocomposites with cellulose nanocrystal was prepared by the solution casting method a composite sheets formed from this material retained its transparency. By the thermogravimetric analysis showed to be thermal stable with a significant enhancement of its storage modulus compared with pure one. The glass transition was also shifted to lower temperatures than the polymer alone. ${ }^{76}$

The cellulose nanocrystals are relatively easy to produce but the main problem with their practical use is related to the homogeneous dispersion within a polymeric matrix.. A new process to avoid this problem was their transformation into a co-continuous material involving the surface chemical modification of the nanoparticles through grafting agents containing a reactive end group and a long compatibilizing tail. ${ }^{77}$

Cellulosic nanoparticles obtained from a combination of mechanical shearing, and enzymatic and acid hydrolysis of sisal fibers was used to prepare a nanocomposite with natural rubber. The acid hydrolysis treatment on microfibrillated cellulose exerted an effect on the composite increasing the elongation at break and the modulus increased with the temperature of the treatment. However, in the enzymatic treatment performed before or after the mechanical shearing leads to different stiffer materials. The authors suggested that is more beneficial to first treat the fibers with enzymes and then to mechanically shearing. ${ }^{78}$

Cellulose nanofibers were used as filler in polypropylene composites. SEM analysis showed polymer stretching as the major component causing plastic deformation in fracture surfaces of the nanofibers. Individual fibers were separated and dispersed in the matrix polymer, although considerable agglomeration was observed beyond $6 \%$ filler loading, which resulted in sustained tensile and flexural strength. ${ }^{79}$

As we can see in these publications, even all the accumulated research data to use cellulose nanofillers as reinforcements in polymer matrix composites, some problems are yet to be solved. One of these problems is during cellulose nanoparticles drying, because the fibers have a tendency to reaggregate and the nanosize effect could be in certain degree lost. The dispersion of hydrophilic nanoparticles into hydrophobic polymer matrixes is another problem to resolve. This is possible to overcome through surface modification to increase their suitability as reinforcing fillers in polymer matrixes. ${ }^{32}$

\section{Cellulose nanocrystals as control delivery carriers}

Nanocrystal cellulose-heparitin was prepared by dispersing $10-80$ $\mathrm{nm}$ cellulose nanocrystal into water to obtain a suspension, reacting with peroxide under nitrogen protection, and then reacting in polar organic solvents with methacrylic acid, 2-sulfoaminoethyl methacrylate, and 2-sulfatoethyl methacrylate to produce a cellulose-heparitin composite dispersion. The above compounds had the anticoagulation and blood fat dissolving functions of heparitin and long-acting effects, without the blocking of blood vessels and good body compatibility. ${ }^{80}$

Polysaccharides are known as surface coatings for nanoscale drug carriers. Then, cellulose nanocrystals were prepared by sulfuric acid hydrolysis of dissolving grade softwood sulfite pulp and their cytotoxicity was studied, showing them to be non toxic to several cells. For quantitative cell uptake studies, cellulose nanocrystals were labeled with fluorescein isothiocyanate and with human brain microvascular endothelial cells and rat C6 glioma cells, showing a slow uptake of cellulose nanocrystals by the cells. The delivery and targeting of therapeutic and diagnostic agents with cellulose nanocrystals could represented a significant advance in nanomedicine. ${ }^{81}$

In a targeted delivery, cellulose nanocrystals were chosen as the biomaterial. The cellulose nanocrystals were characterized as non-toxic with limited binding/uptake in its untargeted state. Considered an adequate carrier, folic acid was chosen as it is widely known to specifically target folate receptors and this targeting was verified in folate receptor-positive cancer cells. The binding/ uptake results suggest that the folic acid-conjugated cellulose nanocrystals selectively target cells via a folate receptor-mediated mechanism. ${ }^{82}$

A complex nanostructure between a cationic polysaccharide (chitosan) and an anionic cylindral nanoparticles (cellulose nanocrystals) for a potential applications in active delivery was published. The cellulose nanocrystals were obtained from acid hydrolysis from wood pulp and formed particles from nanometers to micrometers depending on the nanocrystal cellulose/chitosan ratio. $^{83}$

Recently, it was demonstrated that nanocrystalline cellulose was capable of binding ionizable water soluble antibiotics tetracycline and doxorubicin. These hydrophilic drugs were rapidly released and this can be controlled by surface modification by binding the cationic surfactant, cetyl trimethylammonium bromide. This latter material was shown to bind significant quantities of the nonionized hydrophobic anticancer agents docetaxel, paclitaxel, and etoposide and release these drugs in a controlled manner and penentrate efficiently cancer cells. $^{84}$

\section{Cellulose nanocrystals and projections}

From all of these data, cellulose nanostructures have an exciting potential as reinforcements in nanocomposites and the surface qualities have a wide variety of applications, such as foams, adhesives, specialized barrier films, drug carriers and electronic display materials. It is important to mention that the potential mechanical properties of cellulose nanofibres could compete in equal or better conditions with other engineering materials, and it is possible to consider that this could be useful in high-end technological applications (Table $1)^{22}$

Table 1. Strength and stiffness of reinforcement materials*.

\begin{tabular}{lll} 
Material & Tensile strength (GPa) & Modulus (GPa) \\
\hline Cellulose nanocrystals & 7.5 & 150 \\
Glass fiber & 4.8 & 86 \\
Steel wire & 4.1 & 207 \\
Kevlar & 3.8 & 130 \\
Graphite whiskers & 21 & 410 \\
Carbon nanotubes & $11-73$ & $270-970$ \\
- &
\end{tabular}

* Referenced from $<$ http://woodscience.oregonstate.edu/faculty/ simonsen>.

It is evident that nanotechnology has the means to revolutionize the forest products industry, through the improvement of the actual products and for new application of cellulose in order to reach new consumers with a new perspective of the traditional forest products (Moon, 2008). ${ }^{6}$ These facts lead us to suggest that the production of cellulose nanostructures from residue of the bioethanol production is very promising, since it would result in lower cost of some of the production steps from lignocellulosic materials. Thus, the inclusion of the production of cellulose nanocrystals in the biorefinery would increase the number of jobs and the profitability of the venture.

But it is of paramount importance to be aware that there are concerns in this area. Since cellulose nanocrystals are one group of nanoparticles that have high potential economic value, exists an important concern for the development of metrology for these nanoparticles and represent a significant challenge. ${ }^{11,12}$ A recent paper discusses some of the instrumentation, metrology and standards issues associated with the promoting up for production and use of cellulose nanoparticles. ${ }^{85}$

\section{Cellulose nanocrystals as co-product in bioethanol production}

Research on new natural and economical bio-active substances, from wood or non-woody materials is a actual challenge nowadays, mainly in the focus of sustainability and bio-refinery concepts.

An interesting economical analysis was applied to estimate several pretreatment costs on a consistent basis in a corn stover, using comparative data on sugar recovery from hemicellulose and cellulose by the combined pretreatment and enzymatic hydrolysis operations. In this analysis the project was introduced and results of this research were reported..$^{86}$

A consortium led by North Dakota State University (NDSU) studied the use cellulose nanofibers derived from wheat straw to make a product that could substitute fiberglass and plastics in many industrial applications. An exhaustive economical analysis for producing cellulose nanowhiskers as a coproduct in an ethanol biorefinery and an ASPEN Plus-based process model (http://www.aspentech.com/core/aspen-plus.cfm) was developed to evaluate ethanol production from wheat straw. The production cost of ethanol including by-product credit was determined at $\$ 0.41$ per liter. When production of cellulose nanowhiskers was added to the base case model, the manufacturing cost of producing these nanoparticles from wheat straw was estimated to be $\$$ 1.25 per $\mathrm{kg}$. These data suggested that production of cellulose nanowhiskers 
would be an enhancement to the economical feasibility of a wheat straw to ethanol production. ${ }^{87}$

Transmission electron microscopy showed that the residuals left, after processing cellulosic biomass for bioethanol, include an important amount of cellulose nanocrystals ${ }^{88}$ especially in a bioethanol production from simultaneous saccharification and fermentation. ${ }^{89,90}$

A recent report on the viability of the residue from a bioethanol process as a simple and low-cost source of raw material for nanowhiskers and the possibility of adding value to the bioethanol process was published and showed that the residue from bioethanol process was found to be as high as $48 \%{ }^{91}$

In a report related to the case for bioethanol cost reductions through generation of a co-product, Winter ${ }^{88}$ hypothesized two assumptions: one assumed, for example, a 90:10 ratio of cellulo-oligomers to nanocrystals, that are important to use in ethanol production and nanocrystals for reinforcing particles in nanocomposites, respectively, and the second considered the values of $\$ 0.22 / \mathrm{kg}$ for the oligomers and $\$ 2.21 / \mathrm{kg}$ for the nanocrystals. Then, $50 \%$ of the value will come from the nanocrystals with no additional enzyme or processing required for the bioethanol. The result is a $50 \%$ reduction in enzyme and preprocessing costs attributable to ethanol with another $50 \%$ attributable to the nanocrystals. ${ }^{88}$

In a study monitoring the molecular weight and crystallinity of bacterial cellulose I and II and microcrystalline cellulose digested with three Thermobifida fusca cellulases, it was shown that cellulose crystallinity was increased slightly with treatment time. The digestion rate of BC-II was higher than that of BC-I for endocellulases. The cellulose acted differently over the different substrates. Endocellulases decreased the molar mass faster than exocellulase, where a slower molar mass loss was observed. Lower conversion rates for microcrystalline cellulose, compared with bacterial cellulose, were found. The authors suggested that possibly the surface area effects may also be important. ${ }^{92}$ TEM micrographs recorded by Goodrich and Winter ${ }^{93}$ indicated that enzyme digestion results in a relatively homogenous distribution of cellulose nanocrystals of approximate length of $350 \mathrm{~nm}$.

Besides traditional valueadded biobased products from traditional wood products such as lumber, paper and paper-derivatives, new commercial probabilities appeared as biorefining to produce energy, fuels, chemicals and syngas. Nanocrystalline cellulose appeared with a high potential impact in this relative by new era as a highvalue byproduct from the biorefining process. This bio-based product could compete with the actual materials and change completely the vision of innovative highstrength biocomposites. ${ }^{94}$

According to a recent Department of Energy (DOE, USA) report, enzyme cost for cellulosic bioethanol is about $\$ 0.68$ per liter (US-DEBP, 2009) ${ }^{95}$, while the target should be $\$ 0.23-0.34$ per liter. Recently Novozymes received two contracts from the DOE for its research efforts to bring down the cost of enzymes and improve their efficiency in converting cellulose to biofuels. The first contract for $\$ 2.2$ million was given in 2002 , and the second for $\$ 12.3$ million was given in 2008. As a result of this work, Novozymes has been able to achieve significant reductions in enzyme costs over the years, notably the 50 percent reduction announced in 2009. Most recently, the company received a \$28.4 million tax credit toward the construction of its enzyme manufacturing facility in Blair, Nebraska, which will create 100 new green jobs. ${ }^{96}$

Domtar Corporation (NYSE/TSX: UFS) and FPInnovations announced (Montreal, July 16, 2010) that they have formed a new joint venture company to build the world's first one metric ton per day commercial-scale nanocrystalline cellulose demonstration plant at the Domtar Windsor, Quebec pulp and paper mill site. Construction will begin in the coming weeks and will take approximately 20 months to be completed. ${ }^{97}$

In a recent paper the aim was to present two examples of research pathways in order to extend the plataform of a common pulp mill. One strategy suggested was the hemicellulose extraction from soft wood before pulping, hydrolyzed into hexoses and then fermented into bio-ethanol. This process gave good results indicating that no active fermentation inhibitors were present in the liquor. The other strategy deal with cellulose nanocrystals from pulp fibers. It is known from the literature that cellulose nanocrystals reinforced polymer nanocomposites exhibited interesting mechanical properties to produce high modulus thin films. These aspects are related to the new biorefinery concept in the pulp and paper industry. ${ }^{98}$

Chile is concern with this important area and the chemical composition of Pinus radiata D. Don trees from different age classes was determined. They studied the hydrolysis with trifluoroacetic acid method in order to analyze the feasibility of using this biomass resource at ages in which, sugar contents result both quality and quantity favorable to produce biofuels (bioethanol process) or chemical compounds (biorefinery process). ${ }^{99}$

\section{Final remarks}

All the data collected on cellulose nanocrystals in term of production, characterization and application suggest that this nanomaterial could easily be extrapolated to bioethanol production. This interesting material has the potential of significantly decreasing the final cost of the enzymes and of all the bioethanol process in such a way that it could be economically feasible to obtain bioethanol and other by- products from lignocelullosic materials such as bagasse, straw or wood resources.

\section{ACKNOWLEDGEMENT}

The support from FAPESP, CNPq and INOMAT (CNPq/MCT) Brazil and from Fondo Nacional de Desarrollo Científico y Tecnológico (FONDECYTChile, grant number 1070492) are acknowledged.

\section{REFERENCES}

1. M.A. Hubbe, O.J. Rojas, L.A. Lucia, M. Sain, BioResources 3, 929, (2008).

2. F.D.E. Goelzer, P.C.S. Faria-Tischer, J.C. Vitorino, M.R. Sierakowski, C.A. Tischer, Mat. Sci. Eng. C. 29, 546, (2009).

3. N. Wang, E. Ding, R. Cheng, Langmuir 24, 5, (2008).

4. Y. Pu, J. Zhang, T. Elder, Y. Deng, P. Gatenholm, A.J. Ragauskas, Composites: Part B: Eng. 38, 360, (2007).

5. S. Elazzouzi-Hafraoui, Y. Nishiyama, J.L. Putaux, L. Heux, F. Dubreuil, C. Rochas, Biomacromolecules 9, 57, (2008).

6. R.J. Moon, MacGraw-Hill Year Book of Science and Technology, McGraw Hill, N. York, pp. 225-228 (2008).

7. M. Postek, E. Brown, Proc. SPIE 10.1117/2.1200903.1474 (2009)

8. A.J. Ragauskas, In Cellulase microfibrills and nanotechnology. June 2007, Portugal. http://ipst.gatech.edu/faculty new/faculty bios/ ragauskas/student_presentations/Portugal_Nanocellulose.pdf.(2007)

9. W. Hamad, Can. J. Chem. Eng. 84, 513, (2006).

10. D.G. Gray, In Towards Understanding Wood, Fibre, and Paper-deeper knowledge through modern analytical tools. Turku / Åbo, May 2008, Final seminar of COST Action E41 \& Workshop of Action E50 (2008).

11. T.H. Wegner, P.E. Jones, Cellulose 13, 115, (2006).

12. M.T. Postek, A. Vladar, J. Dagata, N. Farkas, B. Ming, R. Sabo, T.H. Wegner, J. Beecher, Proc. SPIE, 7042, 70420D (2008); doi:10.1117/12.797575 (2008).

13. M.M.S. Lima, R. Borsali, Macromol. Rapid Commun. 25, 771, (2004).

14. W. Gacitua, A. Ballerini, J. Zhang, Maderas- Cienc. Tecnol. 7, 159, (2005).

15. M.A.S.A. Samir, F. Alloin, A. Dufresne, Biomacromolecules 6, 612, (2005).

16. K.O. Niska, In Eur. Conf. Compos. Mat. Jene, Stockholm. Sweden (2008).

17. D.J. Silva, M.L.O. D'Almeida, O Papel 70, 34, (2009).

18. Y. Habibi, L.A. Lucia, O.J. Rojas, Chem. Rev. 110, 3479, (2010).

19. X. Cao, Y. Habibi, W.L. E. Magalhães, O.J. Rojas, L.A. Lucia, Curr. Sci. 100, 1172, (2011)

20. A. Dufresne, J. Nanosci. Nanotechnol. 6, 322, (2006)

21. A. Dufresne, Can. J. Chem. 86, 484 (2008).

22. S.J. Eichhorn, A. Dufresne, M. Aranguren, N.E. Marcovich, J.R. Capadona, S.J. Rowan, C. Weder, W. Thielemans, M. Roman, S. Renneckar, W. Gindl, S. Veigel, J. Keckes, H. Yano, K. Abe, M. Nogi, A.N. Nakagaito, A. Mangalam, J. Simonsen, A.S. Benight, A. Bismarck, L.A. Berglund, T. Peijs, J. Mater. Sci. 45, 1, (2010).

23. I. Siró, D. Plackett, Cellulose 17, 459-494, (2010).

24. R.J. Moon, A. Martini, J. Nairn, J. Simonsen, J. Youngblood, Chem. Soc. Rev. DOI: $10.1039 / \mathrm{c} 0 \mathrm{cs} 00108 \mathrm{~b}$ (2011).

25. E. Dujardin, M. Blaseby, S. Mann, J. Mater. Chem. 13, 696, (2003).

26. S. Beck-Candanedo, M. Roman, D.G. Gray, Biomacromolecules 6, 1048, (2005).

27. D. Bondeson, A. Mathew, K. Oksman, Cellulose 13, 171, (2006).

28. E.C. Ramires, A. Dufresne, Tappi J. 10, 9, (2011).

29. Y. Habibi, L. Foulon, V. Aguié-Béghin, M. Molinari, R. Douillard, J. Colloid Interf. Sci. 316, 388, (2007).

30. O. Van den Berg, J.R. Capadona, C. Weder, Biomacromolecules 8, 1353 , (2007).

31. N. Wang, E. Ding, R. Cheng, Polymer 48, 3486, (2007).

32. B.S. Purkait, D. Ray, S. Sengupta, T. Kar, A. Mohanty, M. Misra, Ind. Eng. Chem. Res. 50, 871, (2011). 
33. R. Braun, J.R. Dorgan, J.P. Chandler, Biomacromolecules 9, 1255, (2008).

34. B. Jean, F. Dubreuil, L. Heux, F. Cousin, Langmuir 24, 3452, (2008).

35. P.B. Filson, B.E. Dawson-Andoh, Bioresource Technol. 100, 2259, (2009a)

36. P.B. Filson, B.E. Dawson-Andoh, Bioresource Technol. 100, 6661, (2009b)

37. J.P. Pandey, C.S. Kim, W.S. Chu, C.S. Lee, D.Y. Jang, S.H. Ahn, E-Polymers 102, 1, (http://www.e-polymers.org) (2009).

38. E. Kontturi, T. Vuorinen, Cellulose 16, 65, (2009).

39. Q. Li, S. Renneckar, Cellulose, 16, 1025, (2009).

40. M.F. Rosa, E.S. Medeiros, J.A. Malmonge, D.F. Wood, L.H.C. Mattoso, W.J. Orts, S.H. Imam, In $11^{\text {th }}$ Intern. Conf. on Advanced MaterialsICAM-2009, September, Rio de Janeiro, Brazil. (2009).

41. M.F. Rosa, E.S. Medeiros, J.A. Malmonge, D.F. Wood, L.H.C. Mattoso, W.J. Orts, S.H. Imam, In $18^{\circ}$ Congr. Brasil. Eng. Cienc. Mat.-CBIMAT, November, Porto de Galinhas, PE, Abstr. 202-163 (2008).

42. R. Li, J. Fei, Y. Cai, Y. Li, J. Feng, J. Yao, Carbohydr. Polym. 76, 94, (2009).

43. A.F. Turbak, F.W. Snyder, K.R. Sandberg, J. Appl. Polym. Sci. Appl. Polym. Symp. 37, 815, (1983).

44. M.O. Seydibeyoglu, K. Oksman, Compos. Sci. Technol. 68, 908, (2008).

45. L. Wagberg, G. Decher, M. Norgren, T. Lindstrom, M. Ankerfors, K. Axnas, Langmuir 24, 784, (2008).

46. S.Y. Lee, S.J. Chun, I.A. Kang, J.Y. Park, J. Ind. Eng. Chem. 15, 50, (2009).

47. A. Bendahou, H. Kaddami, A. Dufresne, Eur. Polym. J. 46, 609-620, (2010).

48. M. Paakko, M. Ankerfors, H. Kosonen, A. Nykanen, S. Ahola, M. Osterberg, J. Ruokolainen, J. Laine, P.T. Larsson, O. Ikkala, T. Lindstrom, Biomacromolecules 8, 1934, (2007).

49. L. Jiang, X. Chen, Z. Li, Huaxue Yu Shengwu Gongcheng 25, 63, (2008b).

50. P.B. Filson, B.E. Dawson-Andoh, D. Schwegler-Berry, Green Chem. 11, 1808, (2009).

51. J. George, K.V. Ramana, A.S. Bawa, Siddaramaiah, Inter. J. Biol. Macromol. 48, 50, (2011).

52. P. Satyamurthy, P. Jain, R.H. Balasubramanya, N. Vigneshwaran, Carbohydr. Polym. 83, 122, (2011).

53. S. Dong, M. Roman, J. Am. Chem. Soc. 129, 13810, (2007).

54. Y. Habibi, A. Dufresne, Biomacromolecules 9, 1974, (2008).

55. L. Jiang, E. Morelius, J. Zhang, M. Wolcott, J. Holbery, J. Composit. Mat. 42, 2629, (2008)

56. M.J. Cho, B.D. Park, J. Ind. Eng. Chem. 17, 36, (2011).

57. A.P. Lemes, R. Gonçalves, A.M. Moretti, P.D. Marcato, N. Durán, In VII Meeting of SBPMat-2008 - VII Ann. Meeting of the Braz. Soc. Res. Mat. September, Guarujá-SP, Brasil Abstr. B566 (2008).

58. E. Ten, J. Turtle, D. Bahr, L. Jiang, M. Wolcott, Polymer, 51, 2652, (2010).

59. J.R. Capadona, K. Shanmuganathan, S. Trittschuh, S. Seidel, S.J. Rowan, C. Weder, Biomacromolecules 10, 712, (2009).

60. A. Bendahou, H. Kaddami, M. Raihane, Y. Habibi, A. Dufresne, Rev. Roumaine Chim. 54, 571, (2009).

61. N.L. Garcia, L. Ribba, A. Dufresne, M.I. Aranguren, S. Goyanes, Macromol. Mat. Eng. 294, 169, (2009).

62. A.J. De Menezes, G. Siqueira, A.A.S. Curvelo, A. Dufresne, Polymer 50, 4552, (2009).

63. K. Oksman, A.P. Mathew, M. Sain, Plastics Rubber Compos. 38, 396, (2009).

64. G. Morandi, L. Heath, W. Thielemans, Langmuir 25, 8280, (2009).

65. G. Siqueira, H. Abdillahi, J. Brás, A. Dufresne, Cellulose 17, 289-298, (2010).

66. I. Kvien, B.S. Tanem, K. Oksman, Biomacromolecules 6, 3160, (2005).

67. J.K. Pandey, C.S. Lee, S.H. Ahn, J.. Appl. Polym. Sci. 115, 2493, (2010)

68. D.Y. Liu, X.W. Yuan, D. Bhattacharyya, A.J. Easteal, Express Polym. Lett. 4, 26, (2010).

69. K. Shanmuganathan, J.R. Capadona, S.J. Rowan, C. Weder, J. Mat. Chem. 20, 180, (2010).

70. K.S. Mikkonen, A.P. Mathew, K. Pirkkalainen, R. Serimaa, C. Xu, S. Willfor S, Oksman K, Tenkanen., Cellulose 17: 69-81, (2010).

71. J.C. De Mesquita, C.L. Donnici, F.V. Pereira, Biomacromolecules 11, 473, (2010).

72. M.L. Auad, M.A. Mosiewicki, T. Richardson, M.I. Aranguren, N.E.
Marcovich, J. Appl. Polym. Sci. 115, 1215, (2010).

73. M.A. Mosiewicki, V.M. Wik, M.I. Aranguren. Plastic Res. online, 10.1002/spepro.003617, 1-2, (2011).

74. V.M. Wik, M.I. Aranguren, M.A. Mosiewicki. Polym. Eng. Sci. DOI: 10.1002/pen.21939 (2011).

75. R. Rusli, K. Shanmuganathan, S.J. Rowan, C. Weder, S.J. Eichhorn, Biomacromolecules 12, 1363 (2011).

76. H. Liu, D. Liu, F. Yao, Q. Wu, Bioresource Technol. 101, 5685, (2010)

77. A. Dufresne, Molecules, 15, 4111 (2010).

78. G. Siqueira, S. Tapin-Lingua, J. Bras, D.S. Perez, A. Dufresne. Cellulose, 18, 57, (2011).

79. D.J. Gardner, Wood Fiber Sci. 43, 1, (2011).

80. D. Wang, G. Li, Y. Huang, Faming Zhuanli Shenqing Gongkai Shuomingshu. Patent CN 1491976 A 20040428 (2004).

81. M. Roman, S. Dong, A.A. Hirani, Y.W. Lee, In 235th ACS National Meeting, New Orleans, LA, United States. Abstr. CELL-030 (2008).

82. A. Hirani, Master of Science Thesis. Biomedical Engineering and Sciences. Virginia Polytechnic Institute and State University (2009).

83. H. Wang, M. Roman, Biomacromolecules 12, 1585, (2011).

84. J.K. Jackson, K. Letchford, B.Z Wasserman, L. Ye, W.Y Hamad, H.M Burt, Inter. J. Nanomed. 6, 321, (2011).

85. M.T Postek, A. Vladar, J. Dagata, N. Farkas, B. Ming, R. Wagner, A. Raman, R.J. Moon, R. Sabo, T.H Wegner, J. Beecher, Meas. Sci. Technol. 22, 024005, (2011).

86. C.E. Wyman, B.E. Dale, R.T. Elander, M. Holtzapple, M.R. Ladisch, Y.Y. Lee, Bioresource Technol. 96, 1959, (2005).

87. F.L. Leistritz, D.M. Senechal, M.D. Stower, W.F. McDonald, C.M. Safron, N.M. Hodur, Agribussines and Applied Economic Report N 590. http://ageconsearch.umn.edu/handle/23500. (2006).

88. W.T. Winter, In Div. Cell. Renew. Mat. 233rd ACS Nat. Meeting, Chicago, Il. March (2007)

89. N. Durán, A.P. Lemes, M. Durán, P.D. Marcato, J. Freer, J. Baeza, H. Franco, In Intern. Conf. Food Agric. Appl. Nanotechnol (NanoAgri-2010), São Carlos, S.P., Brazil (2010)

90. H. Franco, R.T. Mendonça, P.D. Marcato, N. Durán J. Freer, J. Baeza, Bioresource Technol Submitted (2011).

91. K. Oksman, J.A. Etang, A.P. Mathew, M. Jonoobi, Biomass Bioener. 35, $146(2011)$.

92. Y. Chen, A.J. Stipanovic, W.T. Winter, D.B. Wilson, Y.J. Kim, Cellulose 14, 283, (2007).

93. J.DF. Goodrich, W.T. Winter, Biomacromolecules 8, 252, (2007).

94. J.E. Winandy, A.W. Rudie, R.S. Williams, T.H. Wegner, Forest Prod. J. 58, $8,(2008)$.

95. US-DEBP-2009: US. Depart. Energy Biomass Program. September. http://www1.eere.energy.gov/biomass/pdfs/biomass_deep_dive_pir.pdf. (2009).

96. Novozymes-2010.http://www.novozymes.com/en/MainStructure/ PressAndPublications/ Newsitems/2010/Car+on+paper+waste.htm. (2010).

97. Domtar and FPInnovations. http://www.fpinnovations.ca/pdfs/ BinderEn.pdf, assessed in May 14, 2011.

98. C. Chirat, D. Lachenal, A. Dufresne. Cellulose Chem. Technol., 44, 59, (2010)

99. A. Berrocal, J. Baeza, J. Rodriguez, M. Espinosa, J. Freer, J. Chilean Chem. Soc. 49, 251, (2004). 